\title{
A especularidade na produção jornalística de Clarice Lispector
}

\author{
MARIÂNGELA ALONSO
}

Universidade de São Paulo

\begin{abstract}
This article aims to understand the narrative technique of mise-enabyme in Clarice Lispector's short story "A quinta história" (published in A legião estrangeira (1964)). Here Lispector quickly builds variations on the same argument, a sort of unfolding of stories that succeed each other, originating in the same idea: how to kill cockroaches. Based on the studies of Lucien Dällenbach and Verónique Labeille among others, the article confronts the versions of $A$ quinta história in the periodicals Casa e Jardim and Senhor, focusing on miseen-abyme as the seminal and questioning force of Lispector's work.
\end{abstract}

Keywords: Mise-en-abyme, A quinta história, mirrors, prism, otherness

É curioso quando o procedimento da intertextualidade se pauta no trabalho de resgate de textos de um mesmo autor, reescrevendo-se em outro texto, no movimento de remissão à própria obra, dando origem ao fenômeno da chamada autotextualidade ou intratextualidade, conforme a nomenclatura de Gérard Genette. Como exercício de reenvio a outros textos, a autotextualidade ou intratextualidade constitui-se numa forma específica de transtextualidade, apresentando especificidades. Frequentemente os teóricos discriminam "intertextualidade interna" e "externa," como é o caso de Jean Ricardou. Ao discutir a unidade da obra literária e a noção de autor, o estudioso estabelece as diferenças, indicando a "intertextualidade externa" como a relação de um texto com outro texto, distinguindo-a da "intertextualidade interna," cuja relação é pautada por um texto consigo mesmo. No colóquio sobre o escritor Claude Simon ocorrido em Cerisy-la-Salle (1974), Ricardou conceitua a "intertextualidade 
geral" como as relações intertextuais entre textos de autores diferentes, e a "intertextualidade restrita," por sua vez, demarcada pelas relações entre textos de um mesmo autor (Ricardou; Dallenbach, "Intertexto e autotexto").

A partir da distinção postulada por Ricardou, Lucien Dällenbach ("Intertexto e autotexto") admite a existência da chamada "intertextualidade autárquica," designando-a por "autotextualidade," como o fez Genette. Em sua especificidade, o fenômeno do autotexto pode ser caracterizado como uma "reduplicação interna" da obra literária, no sistema das "relações possíveis dum texto consigo mesmo" (Dallenbach, "Intertexto e autotexto" 52), ao desdobrar a narrativa toda ou em parte sob as dimensões "literal" (a do texto, no sentido estrito) ou "referencial" (a da ficção). Além disso, Dallenbach indica três artifícios da especularidade, a saber: reflexão simples, infinita e aporística. Conforme detalharemos a seguir, esta tríade aparece amalgamada na obra clariciana, de modo a marcar um jogo prismático de quebra-cabeças, cujo sentido se encontra na composição do todo. Assim, espera-se enfocar o procedimento narrativo da mise-en-abyme e a linguagem matemática como emblemas criativos e questionadores da ficção de Clarice, especialmente no que se refere à noção de homotetia textual e geometria nas versões do conto A quinta história publicados nos periódicos Casa e Jardim e Senhor.

Em linhas gerais, o procedimento narrativo da mise-en-abyme caracteriza-se pela autotextualidade ou reduplicação interna da obra, demonstrado nas relações possíveis dum texto consigo mesmo, viabilizando os processos de iteração e especularidade. Para dar início à discussão, Dällenbach retoma os apontamentos do escritor francês André Gide a respeito das imagens da heráldica:

Gosto que em uma obra de arte se encontre assim transposto, à escala dos personagens, o pano de fundo desta obra. Nada o esclarece melhor nem estabelece mais seguramente todas as proporções do conjunto. Assim, nos quadros de Memling ou de Quentin Metzys, um pequeno espelho convexo e escuro reflete, por sua vez, o interior de um cômodo onde se representa a cena pintada. Assim, no quadro das Meninas de Velásquez (mas um pouco diferentemente). Enfim, em literatura, em Hamlet, a cena da comédia; e alhures em muitas outras peças. (Le recit spéculaire 15 , tradução nossa) 
De acordo com os heraldistas, o escudo é o elemento central do brasão; é nele que estão contidos os caracteres distintivos (Zuquete). O termo abyme, por sua vez, alude ao centro do escudo, quando as peças aí inseridas portam dimensões menores, revelando um espaço de miniaturização de figuras, configuração que levou Gide a perfilhar por analogia o procedimento do encaixe narrativo:

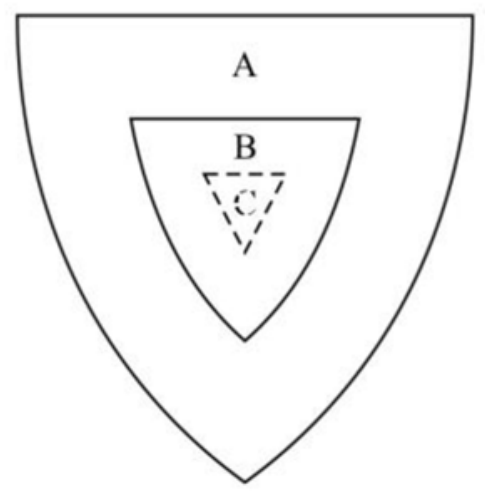

Figura 1: O brasão

(Dallenbach, Le recit spéculaire 143)

Não são poucos os estudiosos que se debruçaram sobre o procedimento da miseen-abyme e sua especularidade, haja vista a diversidade de expressões utilizadas, conferindo ao termo riqueza simbólica e estrutural advinda de domínios artísticos diversos.

Umberto Eco dedica-se à questão do espelho, definindo espelho como "qualquer superfície regular capaz de refletir a radiação luminosa incidente" (13). Tal superfície pode ser plana ou curva, sólida ou líquida, capaz de captar e revelar imagens em sua suprema singularidade. Na esteira da semiótica, Eco estabelece uma espécie de "pragmática do espelho," atentando para a relação de dependência que o espelho, como um fenômeno físico, mantém com o objeto. Desse modo, conclui que o fenômeno especular não constitui um signo, visto que não se pode universalizá-lo: "Se o espelho nomeia (mas, claramente, trata-se de uma metáfora), ele nomeia um só objeto que está na sua frente. Em outras palavras, o que quer que seja uma imagem especular, esta é determinada nas suas origens e na sua subsistência física por um objeto a que chamaremos referente da imagem" (21). A fim de explanar e tornar mais clara a especularidade da figura heráldica tomada por Gide, Dällenbach (Le livre et ses miroirs) atenta para as 
comparações à exaustão com as bonecas russas e as caixas chinesas, as quais se engendram umas às outras, bem como as pirâmides mexicanas, que se encaixam e se refletem mutuamente; os cartazes publicitários, reproduzindo seus motivos ao infinito e em perspectiva e ainda a famosa fita de Moebius, cujas faces interna e externa permutam-se, invertendo sua identidade.

A pluralidade de comparações em torno do conceito de mise-en-abyme e sua especularidade permite acrescentarmos a chamada geometria dos fractais, teoria elaborada pelo matemático polonês Benoît Mandelbrot em 1975. Proveniente do latim fractus, o termo "fractal" deriva do verbo frangere, cujas significações abrangem os sentidos de quebrar, fender-se, ou seja, "criar fragmentos irregulares, fragmentar" (Barbosa 9). Diante desta noção, Mandelbrot desenvolveu estudos de formas e padrões geométricos que se repetiam infinitamente, ainda que restritos a um espaço finito. Assim, os fractais constituem-se em formas determinadas pela propriedade de autossemelhança, visto que uma parte da figura reflete, de modo exato ou aproximado, sua totalidade. O melhor exemplo é o estudo realizado nas costas da Bretanha, em que cada trecho, com seus cabos e baías, é similar a uma miniatura de todo o litoral:

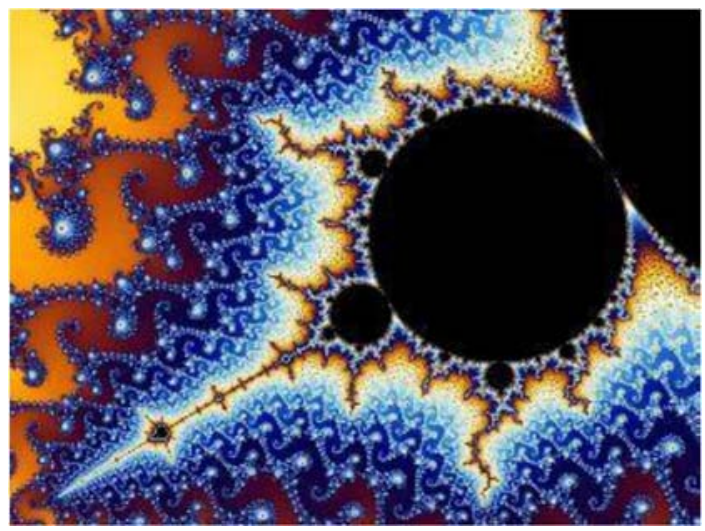

Figura 2: Conjunto de Mandelbrot (fractal matemático) Fonte: www.fsf.org (Free Software Foundation).

A geometria dos fractais estende-se a diferentes áreas do conhecimento, tais como às ciências naturais, no que tange ao formato e dimensões de nuvens, 
relâmpagos, plantas e árvores, bem como a outros campos, sendo a computação, a engenharia, a biologia, a geografia, a física, a arte, entre outros.

A capacidade reveladora de permitir o alcance de elementos não acessíveis à visão pura torna possível a discussão em torno da intrigante estrutura abismal presente nos espelhos. Nesse contexto, a mise-en-abyme surge como procedimento narrativo associado à função especular, caracterizando-se como um instrumento de realce à imagem refletida em sua duplicidade. Seu funcionamento reitera os contornos e propriedades do objeto refletido. $\mathrm{O}$ entendimento do vocábulo perpassa, na escala de personagens da obra literária, o redobramento do próprio sujeito da narrativa, num movimento reflexivo, conforme lembra Dällenbach: "O que primeiro cabe evidenciar, é que a obra de arte reflexiva é uma representação - e uma representação dotada dum grande poder de coesão interna" ("Intertexto e autotexto" 67-68). Após discutir a acepção original do vocábulo, o estudioso salienta que o procedimento visa agrupar, por vezes, um conjunto de realidades resumido por meio de três figuras essenciais, segundo o tipo de reflexão/reduplicação estabelecido: reflexão simples, infinita e aporística. O primeiro tipo aborda o fragmento que mantém com a obra que o inclui uma relação de semelhança; o segundo traz relatos semelhantes contidos uns nos outros; o terceiro e último caracteriza-se pelas histórias encaixadas umas nas outras, as quais se confundem no texto. Segundo Dällenbach, os três modos descritos não deixam de remeter um ao outro, revelando a tomada de posicionamentos críticos e estéticos, além de problematizarem a construção romanesca associada à metáfora do espelho: "Na medida em que essas três reduplicações podem todas, em certo sentido, se reportar a uma outra modalidade da reflexão especular, explica-se o valor emblemático do qual o espelho se encontra investido em grande número de críticos" (Le recit spéculaire 51). Pode-se dizer que os três artifícios de especularidade apontados por Dällenbach surgem amalgamados nas narrativas de Clarice Lispector, fazendo de sua obra um constructo semelhante a um quebracabeça, cujas peças prismáticas ganham sentido quando inseridas todas juntas.

A partir das considerações de Matthew Escobar sobre a mise-en-abyme, Véronique Labeille reforça o princípio de semelhança entre os três tipos elencados na teoria de Dällenbach, abordando a importância da reflexividade presente no conceito. Para a pesquisadora, a técnica de mise-en-abyme caracteriza-se por um alto teor de reflexividade, o qual deve ser captado com a 
ajuda de ferramentas críticas e sócio críticas da obra literária. Mais do que um espelho, há, na mise-en-abyme, uma espécie de caleidoscópio ou fractal que fornece, à luz de diferentes ângulos, pela sua reduplicação, não somente o encaixe narrativo presente, mas também a atualidade contemporânea, social e artística da obra literária. Assim, Labeille propõe a imagem de um "prisma" em substituição à do espelho: "Mais ainda, para permanecer na metáfora ótica, propomos a figura do prisma, espelho quebrado, permitindo intervalos entre a imagem e o seu reflexo" (104). Configura-se em "A quinta história" uma espécie de estrutura abismal, uma vez que o conto é dotado de reflexão infinita nas variações de mesmo tema, cujas voltas são entrecortadas pela obsessão da narradora em eliminar baratas por meio de uma receita caseira. O texto, como uma combinatória matemática de rede infinita, multiplica as narrações, dialogando com as estruturas encaixadas dos contos milenares de As mil e uma noites. Nessa ciranda especular, as imagens das baratas voltam obsessivamente e a autora apresenta ao leitor uma literatura com forte capacidade reflexiva.

A presença do campo matemático possibilita um encontro com o que Dällenbach concebe como "suporte temático" da mise-en-abyme. Para o teórico, a técnica só alcança "o pleno regime" quando subscrita ao lado de exemplos relanceados por "pintura, peças de teatro, fragmentos de música, romance, conto, novela, tudo se passa como se a reflexão, para levantar vôo, devesse pactuar com uma realidade homogênea da que reflete: uma obra de arte" ("Intertexto e autotexto" 67). Embora o estudioso não mencione a matemática, podemos aqui inseri-la, uma vez que é possível encontrar relações estruturais semelhantes entre esta ciência e a literatura, sobremaneira no que tange aos textos que apresentam em suas bases certas questões, como os problemas de ordem lógica ou de análise combinatória, cuja dinâmica contribui para um melhor entendimento e potencialidade da obra literária. Sem perder de vista os pressupostos teóricos apresentados, discutiremos a seguir as versões de "A quinta história," examinando alguns pontos fulcrais de sua construção, os quais estão diretamente ligados à mise-en-abyme e seu funcionamento.

\section{Revistas, baratas e espelhos}

Como sói acontecer em toda a produção clariciana, os contos têm como base a consciência individual do sujeito e seu relacionamento com o outro. Engendra- 
se um mundo rico em possibilidades de constituição do sujeito, que pode ser representado ora pela visão de um cego mascando chicles, ora pelo vislumbre de um búfalo no jardim zoológico, ou ainda pelo universo povoado de galinhas, cavalos e baratas, sinalizando eternamente o itinerário de um eu que se descobre outro (Souza). Desvela-se então o processo de estrangeiridade pensado em sua condição paradoxal, tal como afirmara o poeta francês Arthur Rimbaud (18541891): “eu é um outro.” Na alteridade dos seres apreendidos e confrontados pela autora encasula-se algo do próprio ser, sua matéria primordial e agônica. Assim, continuando a percorrer os objetivos deste artigo, enfocaremos o conto "A quinta história" e a ocorrência da mise-en-abyme. Tal como ocorre com as receitas caseiras de como eliminar baratas, uma dona de casa depara-se com o estrangeiro de si mesma na medida em que se propõe a aniquilar obsessivamente os insetos. As implicações estruturais em abismo serão aqui abordadas, por meio da fundamentação teórica que estamos discutindo, além da inserção de outros estudos, os quais alargarão o horizonte de análise do tema proposto.

A direção escolhida para a pesquisa levou-nos à necessidade de averiguar as versões de "A quinta história" com mais profundidade, resultando no exame das composições presentes em Casa e Jardim e Senhor. Desse modo, essa contribuição à obra de Clarice Lispector tem como objetivos levantar e descrever uma parte do processo de gênese de sua criação pelo exame do "caso clássico" da barata e suas implicações com o procedimento da mise-en-abyme. A fim de tornar mais clara nossa discussão acerca da mise-en-abyme, realizaremos o cotejamento das versões do conto "A quinta história" publicadas nas revistas Casa e Jardim e Senhor acima mencionadas, tomando como eixo de comparação a versão já em livro publicada em A legião estrangeira, uma vez que a autora não realizou alterações depois desta publicação. Estamos nos referindo às versões publicadas no Jornal do Brasil ("Cinco relatos e um tema") e em Felicidade clandestina.

O conto "A quinta história" aparece pela primeira vez em outubro de 1960 na revista Casa e Jardim. Posteriormente, o conto ressurgiu em abril de 1962 na revista Senhor, mais precisamente na coluna intitulada "Children's Corner." Foi aqui que a escritora publicou em primeira mão alguns de seus contos mais representativos, que mais tarde também seriam publicados em livros. Além disso, a narrativa despontou em 1964 no volume A legião estrangeira, foi ainda republicada no Jornal do Brasil em julho de 1969 como "Cinco relatos e um 
tema" e em 1984 apareceu na edição póstuma das crônicas de A descoberta do mundo. O texto também foi inserido na coletânea Felicidade clandestina, de 1971.

Pouco se sabe a respeito da atuação de Clarice no periódico Casa e Jardim e quanto tempo durou sua colaboração. Além de Clarice, a publicação contou com textos de autores como Carlos Drummond de Andrade e Mário Quintana. Lançada em 1953 pela editora Monumento, Casa e Jardim foi uma das primeiras publicações sobre arquitetura, decoração e paisagismo no Brasil. A partir de 1965 passou a ser publicada pela editora Fernando Chinaglia e em 1998 foi comprada pela editora Globo. Em 1965 a grafia do título sofreu alteração, passando de Casa e Jardim para Casa \& Jardim, formato conservado até hoje, pois a revista continua em circulação. ${ }^{1}$

Dirigida ao público leitor da classe média, o periódico privilegiava a figura da "dona de casa moderna," oferecendo-se como guia prático do lar num período em que o país passava por um acelerado processo de urbanização e industrialização. Acompanhando este contexto promissor da sociedade brasileira, a revista valorizou a arquitetura e os interiores modernos, viabilizando os liames entre o estilo de vida despojado e a funcionalidade de espaços e artefatos. Como se pode notar na matéria intitulada "Os móveis e o modernismo," de Edimilson Viana Moura:

A arte dos móveis no século XX toma suas novas formas de expressão da arquitetura, subordinando sua estrutura às necessidades da vida moderna. [...] Como nos edifícios, a construção do mobiliário moderno acusa claramente os elementos componentes, de tonalidades puras, abolindo por completo o artificialismo dos detalhes. Os acessórios decorativos, como a douração e a incrustação, são destronados, buscando-se a beleza na ponderação e no equilíbrio da forma, na vivacidade da cor e na riqueza natural do material empregado. (Santos e Pedro 7)

Logo, o periódico cumpria uma função importante na divulgação de comportamentos de consumo e estilos de vida da leitora da época.

\footnotetext{
${ }^{1}$ Respeitaremos a grafia original por estarmos tratando de um texto publicado em 1960.
} 
Dentre as reportagens trazidas pela revista estava a apresentação de comentários de especialistas em torno da decoração de casas pertencentes às pessoas refinadas e caracterizadas pelo seu "bom gosto." Além das matérias acerca de decoração e jardinagem, havia ainda as que abordavam comportamento, culinária e bordado, surgindo entremeadas aos projetos de grandes nomes da arquitetura, como Rino Levi, Flávio de Carvalho e Artacho Jurado. A narrativa de "A quinta história" teve lugar na revista Casa e Jardim (vol. 69, out. 1960, p. 6), em página inteira. Sem grandes recursos gráficos, o texto é diagramado em baixo de duas gravuras simples e dividido em duas colunas. $^{2} \mathrm{O}$ texto de Casa e Jardim aparece em formato de narrativa, valendo-se do receituário como mote. Nesse ponto, é importante lembrarmos que a narrativa de "A quinta história" tem, como possíveis embriões, as receitas "Meio cômico, mas eficaz" e "Receita de assassinato (de baratas)," textos publicados por Clarice a partir de pseudônimos, nos periódicos Comício (1952) e Diário da Noite (1960) (Alonso). Tal formato implica uma classificação imprecisa, já que oscila entre o conto, a crônica e a receita: "variações sobre um mesmo tema, como o Samba de uma nota só" (Rosenbaum 200).

Em abril de 1962, o conto "A quinta história” é publicado na revista Senhor. Conforme mencionamos, Clarice aí publicou alguns de seus contos mais representativos, como "Feliz aniversário," "Uma galinha," "A imitação da rosa," "O búfalo," entre outros. A colaboração da escritora em Senhor durou de 1959, ano de lançamento da revista, até meados de 1964, ano de seu fechamento. Dirigido por Nahum Sirotsky, Senhor contou com as colaborações de Clarice e Guimarães Rosa, além de lançar nomes importantes como Paulo Francis, Jaguar, Glauco Rodrigues e Carlos Scliar. A revista chegou a atingir a tiragem de quarenta e cinco mil exemplares, número bastante significativo para a época. A história de sua criação remonta ao ano de 1959, quando o empresário Simão Waissman, um dos sócios da editora Delta Larousse, no Rio de Janeiro, idealiza o projeto arrojado de criar um periódico inusitado para leitores distintos e elitizados.

A revista possuía alta qualidade gráfica para a época e pouca preocupação acerca dos acontecimentos imediatos, dando ênfase a reflexões sobre arte,

\footnotetext{
${ }^{2}$ O texto foi reeditado em Casa e Jardim, vol. 701, jun. 2013, na edição especial de 60 anos da revista.
} 
literatura, cultura e política. A seção "Sr. \& Cia" abria as edições, apresentando temário diversificado ao incluir livros, cinema, teatro e poesia. Os artigos seguiam o mesmo formato, abrangendo desde temas sob o viés da religião a receitas de como escrever um romance policial ou a falta de criatividade na área da educação. Seu perfil era, portanto, heterogêneo, intimista e bem-humorado, conjeturando o empresariado de alto poder aquisitivo, na figura do homem moderno e urbano como leitor. Nesse sentido, a escolha do termo Senhor para o título valida a identidade masculina do periódico, evidenciando a ideia de maturidade e experiência. Como indica a coluna "Bastidores," de julho de 1961 ao definir o perfil dos leitores:

Para nós, o leitor de Senhor é um homem de 30 a 50 anos, com automóvel, casa, bons quadros e livros bem lidos na biblioteca, exigente no vestir, cuidadoso na seleção das bebidas, de paladar apurado, casado com mulher preocupada com as coisas da cultura. [...] É assim, para ele e para ela que a revista é preparada. E a fórmula é simples: reunir numa só publicação tudo o que o homem gosta de ler, precisa ler. (Basso 15)

Como vemos, um dos objetivos do periódico era também atingir o público feminino, consubstanciado nas esposas dos empresários. Além disso, a proposta de ter como público leitor a classe com poder econômico mais alto pretendia levantar fundos de sustentação da revista através dos anúncios.

Lispector adentra no universo de Senhor por meio do convite feito pelo jornalista Paulo Francis. No início as colaborações de Clarice Lispector seguiam por carta, pois a escritora residia nos Estados Unidos. Em 1959 a autora separase do marido e retorna definitivamente ao Brasil, recebendo, com a atuação em Senhor, notoriedade e aceitação dos leitores. As produções entregues à revista provinham dos contos enviados quatro anos antes ao editor José Simeão Leal, que prometera publicá-los junto ao Ministério de Educação e Cultura. Devido ao atraso na publicação, a escritora alegou prejuízo e exigiu a devolução dos textos mediante a restituição do valor que recebera na encomenda para poder encaminhá-los separadamente a jornais e revistas.

É no número 4 da edição de abril de 1962 que desponta o conto "A quinta história." Dividido em duas colunas na página de Senhor, a narrativa é 
diagramada junto à matéria de divulgação e apreciação dos livros Redenção para Job, de Aguinaldo Silva e Histórias de menino, de Jorge Medauar. Assim, são publicados em Senhor os contos "A menor mulher do mundo" (edição de março), "O crime do professor de matemática" (junho), "Feliz aniversário" (outubro) e "Uma galinha" (dezembro). Somente em julho de 1960 Clarice consegue finalmente uma editora para a publicação dos contos retidos e, desse modo, a coletânea Laços de família é lançada pela Francisco Alves, do Rio de Janeiro.

\section{Baratas em cotejo}

Em consequência do critério adotado, há pontos a serem discutidos no cotejo entre as versões de Casa e Jardim e de A legião estrangeira. O primeiro ponto a ser considerado a respeito das duas versões diz respeito à linguagem utilizada pelas revistas, como podemos notar no segundo parágrafo da crônica, publicada em Casa e Jardim: "A primeira, 'Como matar baratas,' começa assim: queixeime de baratas. Uma senhora ouviu-me a queixa. Deu-me a receita de como acabar com elas. Que misturasse, em partes iguais, açúcar, farinha e gesso. O remédio as atrairia como comida que também era. Morreriam. Assim fiz. Realmente morreram." Na versão de A legião estrangeira, temos: “A primeira, 'Como matar baratas', começa assim: queixei-me de baratas. Uma senhora ouviu-me a queixa. Deu-me a receita de como matá-las. Que misturasse em partes iguais açúcar, farinha e gesso. A farinha e o açúcar as atrairiam, o gesso esturricaria o de-dentro delas. Assim fiz. Morreram.” As passagens apontam para um nítido contraste entre a linguagem empregada. A primeira versão conta com a expressão "acabar

com elas," termo de fácil leitura e maior informalidade, em conformidade com a linguagem empregada pela revista; em contraste com a variação "como matálas," no emprego de uma linguagem mais bem acabada e um pouco mais formal na versão em livro. Nessa versão há o acréscimo de maior ênfase e detalhe quanto aos ingredientes empregados na receita. Assim, de "O remédio as atrairia como comida que também era" passa-se a "A farinha e o açúcar as atrairiam, o gesso esturricaria o de-dentro delas," salientando o papel infalível do gesso como elemento importante para favorecer o "crime," ou seja, a estratégia maquiavélica de atrair para matar por dentro, o "de-dentro" dos insetos. Em contrapartida à indecisão seguida de afirmação contida com o verbo "morrer" no futuro do pretérito ("Morreriam”), a frase é mais definitiva na versão de 1964 ao empregar 
o pretérito perfeito: "Morreram." Ambas as versões chamam a atenção para a execução do plano/receita na exímia morte das baratas: "Assim fiz. Realmente morreram"; "Assim fiz. Morreram."

A articulação do plano mortífero também sofre a variação quanto aos verbos e expressões utilizadas ao longo dos textos, como se nota em: "Foi na hora de fazer a mistura que elas se individualizaram" para "Só na hora de preparar a mistura é que elas se tornaram minhas também." Embora a subjetividade esteja presente nas duas versões, há algumas diferenças quanto ao sentido das frases e ao tratamento da narradora em relação aos insetos. Na primeira situação salientase o sentido de particularidade dado aos insetos; na segunda ressalta-se ao sentimento de posse, que resultará na fusão da narradora com as baratas. A versão de Casa e Jardim mantém a postura da narradora como espectadora dos fatos quanto à perseguição que esta empreende aos insetos. Como se nota com o verbo "testemunhar" na primeira pessoa do indicativo, em sinal de presentificação do ocorrido: "Testemunho o primeiro alvorecer de Pompéia." Na versão em livro, temos: "Sou a primeira testemunha do alvorecer em Pompéia." O substantivo "testemunha" parece indicar a situação de maior envolvimento da narradora como "primeira testemunha" do "espetáculo estético" metaforizado no enrijecimento das baratas mortas: "A estetização do mal invade o texto instaurando a desordem de uma estética do negativo" (Rosenbaum 203).

Segue-se a focalização dos insetos mortos com a entrada de uma frase incomum à versão em livro: "Uma, azulada, terá sentido: quem olhar para dentro vira estátua de sal." Na versão posterior há a compensação com: "Enquanto aquela ali, de antena marrom suja de branco, terá adivinhado tarde demais que se mumificara exatamente por não ter sabido usar as coisas com a graça gratuita do em vão: é que olhei demais para dentro de mim! É que olhei demais para dentro de . .." Mesmo com frases diferentes, mantém-se a marca de subjetividade do texto clariciano tanto na revista quanto no conto, uma vez que o texto salienta o olhar para "dentro," para a interioridade. A dona de casa adentra ao desconhecido de si mesma, descobrindo-se criminosa e perversa frente à aparente banalidade da situação: "Teria eu então que renovar todas as noites o açúcar letal? como quem não dorme mais sem o ritmo de um narcótico"; "Eu iria então renovar todas as noites o açúcar letal? como quem já não dorme sem a avidez de um rito." O doce do açúcar atrai e contrasta com a amargura do plano letal, favorecendo a perversidade da situação. Nos dois trechos transcritos, os termos "narcótico" e 
"rito" apontam para o aspecto viciante da situação que envolve a narradora. Porém, essa situação será interrompida com a dedetização do lar nos dois textos: "E é por isso que hoje, com o orgulho da virtude, ostento secretamente no coração uma placa: Esta casa foi dedetizada."

No que tange ao conto, agrega-se uma difícil escolha no ritual de purificação da narradora: "Áspero instante de escolha entre dois caminhos que, pensava eu, se dizem adeus, e certa de que qualquer escolha seria a do sacrifício: eu ou minha alma. Escolhi. E hoje ostento secretamente no coração uma placa de virtude: Esta casa foi dedetizada." Um último ponto a ser considerado diz respeito ao final discordante dos textos. Em Casa e Jardim, se lê o seguinte: "A quinta história chama-se 'Uma alma refeita.' Começa assim: 'queixei-me de baratas,'” enquanto A legião estrangeira apresenta uma versão ligeiramente alterada: "A quinta história chama-se 'Leibnitz e a transcendência do amor na Polinésia.' Começa assim: 'queixei-me de baratas." Após declarar a higienização da casa, a narradora enuncia a quinta e "última" história, retornando o discurso ao início.

A mudança em relação aos títulos das histórias indica uma diferença de tom em cada uma das versões. Na primeira versão, o título "Uma alma refeita" salienta a restauração da alma da narradora pela dedetização, ou seja, pelo "orgulho da virtude," que converteu o ato de matar em ato higiênico. $\mathrm{O}$ título apresenta-se em linguagem adequada ao público que se dirige. Na segunda versão, o título "Leibnitz e a transcendência do amor na Polinésia" aponta para o deslocamento dos fatos narrados para uma instância mais filosófica, enigmática e transcendente, que deixa suspenso o próprio texto, uma vez que esta quinta história não é narrada, retornando à primeira. Aqui o direcionamento da linguagem é outro, sem qualquer esforço por identificação ou proximidade com o leitor: "O título mais parece o de uma tese antropológica de embasamento filosófico" (Kahn 115). Ao tratar da relação obsessiva do extermínio das baratas, a crônica cumpre, num primeiro momento, a finalidade de um dos quesitos da revista, ou seja, prezar pelo bom funcionamento e manutenção da rotina doméstica, colocando em relevo a figura da dona de casa. Entretanto, ao longo do texto percebemos não só o simples extermínio dos insetos, mas já o desenvolvimento de uma relação sádica e obsessiva, que acaba por transformar a narradora personagem em sujeito de um gozo desconhecido: "Medo e rancor guiavam-me. Agora eu só queria gelidamente uma coisa: matar cada barata que existe." Embora procurando escrever sob os preceitos de uma linguagem 
adequada ao público de Casa e Jardim, mais uma vez Clarice pratica a subversão de um gênero, deixando entrever um texto peculiar, numa espécie de laboratório para sua ficção, instigando a leitora "a refletir sobre si mesma e sobre a vida" (Nunes 26).

Comparada à publicação de Casa e Jardim, a versão de Senhor está mais próxima do conto presente em A legião estrangeira. Ao realizarmos o cotejo das duas versões verificamos algumas diferenças. Por exemplo, quanto à passagem abaixo, de Casa e Jardim, que não foi mantida na versão de Senhor, tampouco na de A legião estrangeira: "Uma, azulada, terá sentido: 'quem olhar para dentro vira estátua de sal." A discrepância também está presente no final das narrativas quanto ao título dado à "quinta história" em cada texto: "A quinta história chamase 'Uma alma refeita'. Começa assim: queixei-me de baratas" (Casa e Jardim); "A quinta história chama-se 'Leibnitz e a transcendência do amor na Polinésia.' Começa assim: queixei-me de baratas" (Senhor). A propósito desse ponto, é preciso levar em conta a natureza e o público de cada um dos periódicos. A escrita acompanha os direcionamentos de cada uma das publicações, possibilitando-nos um olhar crítico para o enredo. No primeiro caso, o título "Uma alma refeita" coaduna-se com os propósitos de Casa e Jardim, que privilegiava a figura da dona de casa e o seu zelo pelo bom funcionamento do lar; a revista atua, portanto, por meio de uma linguagem simples ao trazer um título claro, de fácil entendimento, o qual salienta a limpeza e dedetização da casa. Ostentando uma placa de virtude pela limpeza e morte dos insetos, a dona de casa terá a "alma refeita." A mesma placa será ostentada no segundo caso, mas, visando um público mais diferenciado, a linguagem joga com um título de teor mais filosófico e enigmático, avesso a qualquer simplicidade, exigindo maior alcance e reflexão por parte dos leitores, uma vez que a sofisticação de modos e pensamentos era um dos imperativos da revista Senhor. Por isso, "Leibnitz e a transcendência do amor na Polinésia."

De modo semelhante à versão de Casa e Jardim, a de Senhor apresenta a repetição desdobrada da estrutura, espécie de espiral obsessiva, que, operada pela mise-en-abyme, ajusta-se ao eterno retorno das baratas, em clara representação simbólica do "próprio mal que habitaria a alma humana" (Rosenbaum 203). Em meio ao aspecto trivial de uma cena doméstica, a narradora depara-se com o estrangeiro de si mesma frente aos insetos. É possível afirmar que a versão presente em Senhor apresenta uma maior riqueza de detalhes em relação à 
primeira, de Casa e Jardim, uma vez que se caracteriza pelo processo de expansão. Tais detalhes seriam reaproveitados na versão em livro de A legião estrangeira. Assim, o tema comum das baratas é compreendido em sua dinâmica por representar uma cadeia de movimentações, cujas retomadas permitem constatar, num "mesmo desenho," a metamorfose e ao mesmo tempo a permanência de elementos temáticos. Essa dinâmica é marcada pelo prosseguimento e tem por base a similaridade, espécie de homotetia textual. Tal princípio matemático designa uma espécie de "transformação geométrica que altera (por ampliação ou redução) o tamanho de uma figura, mas mantém as características principais, como a forma e os ângulos" (Brasil Escola). Como podemos notar na figura abaixo:

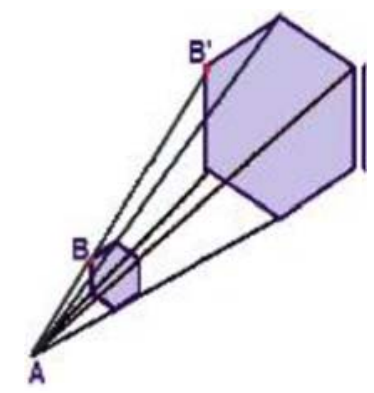

Figura 3: Hexágonos (Ribeiro)

Através de uma relação de homotetia, podemos garantir que os hexágonos são semelhantes, mas o maior tem três vezes o tamanho do menor. Desse modo, a complexidade da escrita clariciana põe em cena a própria relação da obra literária com os processos intertextuais de transformação e transgressão: "a intertextualidade não só condiciona o uso do código, como também está explicitamente presente ao nível do conteúdo formal da obra" (Jenny 6). Pela continuidade temática que apresentam, as versões de "A quinta história" propiciam um elo na cadeia da obra da escritora, que desembocará na narrativa de A paixão segundo G.H. Nos termos propostos por Laurent Jenny, estaríamos diante do princípio de reiteração localizado entre um determinado conteúdo e sua expressão. Segundo Jenny, a sensibilidade dos leitores em relação à repetição pode variar em função de fatores culturais e mnemônicos, bem como aos objetivos e preocupações formais dos escritores: "Os modos de leitura de cada 
época estão igualmente inscritos nos respectivos modos de escrita" (7). Não constituindo exemplos de formas prontas e acabadas, as versões fornecem um efeito estético e lúdico aos leitores. O sentido, desdobrado e ampliado do conto de Lispector aponta para o processo da "transposição," termo reivindicado por Julia Kristeva em relação ao entendimento da intertextualidade: "transposição, que tem a vantagem de precisar que a passagem dum a outro sistema significativo exige uma nova articulação do tético — da posicionalidade enunciativa e denotativa" (59). Como um sistema de signos, o circuito dos contos claricianos viabiliza a retomada, o prolongamento textual e, por sua vez, a apropriação dos leitores.

Não é diferente do que afirma Dällenbach quanto à reflexividade dos textos en abyme:

Em outras palavras, menos imagéticas, um enunciado reflexivo só se torna tal pela relação de desdobramento que ele reconhece com um ou outro aspecto da narrativa - o que, concretamente, equivale a dizer que a emergência dessa relação depende, de um lado, da apropriação progressiva da totalidade da narrativa e, de outro, da aptidão do decodificador em efetuar as substituições necessárias para passar de um registro a outro. (Le recit spéculaire 63)

As considerações acima remetem à própria natureza abrangente da mise-enabyme, uma vez que o elemento reflexivo pode espelhar o conjunto do enredo, estendendo-se além do enunciado aos processos de enunciação e código narrativos: "uma reflexão é um enunciado que remete ao enunciado, à enunciação ou ao código da narrativa" (Dällenbach, Le recit spéculaire 62). De forma lúdica, o processo ocorre na obra de Clarice Lispector com as versões de "A quinta história" em que o mix de textos indica um conjunto ou ciranda temática que se complementa em muitos sentidos, desde a composição dos receituários de como eliminar baratas até a narrativa de A paixão segundo G. H. (1964).

Considerando as versões mencionadas, observamos que Clarice parece adequar-se às linhas editoriais prescritas pelos periódicos, sem deixar de imprimir uma marca peculiar de escrita em tais textos. Desde as publicações em Comício e Diário da Noite, as receitas passam por transformações em seu formato ao transitar de receituários a crônicas e contos, conforme indica 
Aparecida Maria Nunes: "Um trabalho de tecelã. Uma teia que pacientemente foi tecida, aproveitando o mesmo desenho original a cada nova história, mas tornando caminhos diferentes no seu desenrolar" (176). Importa-nos ainda assinalar o hipertexto e hipotexto de que fazem parte as versões de Casa e Jardim e Senhor. Sustenta-se aqui a perspetiva do texto como um mosaico vertiginoso, cujas origens concentram-se em si mesmas, na continuidade do ato de escrever/reescrever semelhante ao ato da serpente que devora a própria cauda, em movimento de eterna busca ou conclusão impossível.

\section{Conclusão}

Este artigo procurou demonstrar a potencialidade da metáfora especular na literatura de Clarice Lispector. A fim de demonstrar o movimento caleidoscópico da escrita clariciana como objeto no qual se projeta uma força expressiva e reflexiva, centrada no procedimento da mise-en-abyme, foi necessário delimitar um corpus capaz de demonstrar essa condição. Para tanto, foram escolhidas as versões do conto "A quinta história" publicadas nos periódicos Casa e Jardim e Senhor, nas quais a literariedade envolta no aproveitamento da especularidade se realizou com muita criatividade e habilidade. Com efeito, os textos revelaramse, antes de tudo, partícipes de um jogo vertiginoso e labiríntico, cujo desafio foi o de acompanhar o trajeto das peças jogadas pela autora, ao mesmo tempo em que tateávamos um entendimento ou interpretação.

Ao modo de uma combinatória matemática de rede infinita, "A quinta história" multiplica as narrações por meio de uma estrutura concêntrica, cujas voltas são entrecortadas pela obsessão da personagem em eliminar os insetos. O conto nos conduz ao questionamento de seus elementos constitutivos, imbricados no mistério da criação de Clarice Lispector. Como postulara Dällenbach, as análises em torno das mises en abyme restariam mutiladas e incompletas, caso o leitor não se voltasse sobre os seus "suportes temáticos": "Mas, esta busca dentro e no meio da narrativa, não seria a busca da narrativa em si ao encontro de seu lugar e de seu tópico?" (Le livre et ses miroirs 91). Ademais, a especularidade tem lugar privilegiado na obra clariciana, cujas ocorrências corroboram uma ficção errática, em constante tecimento. Os jogos especulares são sofisticados e ambíguos, ultrapassando a retroação heráldica para atingir níveis maiores de complexidade, trazendo, por vezes, um espelho invertido e partido, cujos cacos 
atestam a multiplicidade de imagens e formas impossíveis de serem representadas, ao modo de um quiliágono. $\mathrm{O}$ espelho é aqui entendido como um processo fulcral de escrita, medula óssea de uma literatura que se dobra, desdobra e redobra em si mesma, revelando-se múltipla, caleidoscópica.

A peculiaridade deste aspecto é destacada por Yudith Rosenbaum ao abordar a fatura de "A quinta história": "trata-se de uma 'repetição diferencial', pois o retorno parece carregar em si o germe do que se renova" (203). A repetição sistemática surge, portanto, como o elemento primordial para a escritora pensar a própria obra: "a repetição me é agradável, e repetição acontecendo no mesmo lugar termina cavando pouco a pouco, cantilena enjoada diz alguma coisa" ("A explicação que não explica" 240). Nesse sentido, a repetição atua como um dos desafios à obra clariciana ao mesmo tempo em que invoca a compreensão da especularidade do texto, lançando a ele um olhar mais crítico e diferenciado. Como bem observa Compagnon: “interpretar um texto é sempre, inevitavelmente, com a identidade, produzir a diferença, com o mesmo, produzir o outro: descobrimos diferenças sobre um fundo de repetições" (68). E assim lembramos a resposta de Lispector ao ser questionada sobre as obras que mais a aproximavam do público jovem. Ao discutir os contrastes da recepção de $A$ paixão segundo G.H por um professor e uma moça de dezessete anos, afirma:

Suponho que entender não é uma questão de inteligência e sim de sentir, de entrar em contato. Tanto que o professor de português e literatura, que deveria ser o mais apto a me entender, não me entendia $[\ldots]$ E a moça de dezessete anos lia e relia o livro. Parece que eu ganho na releitura, não é? O que é um alívio. ("Entrevista”)

Diante disso, é forçoso concluir que seria impossível imaginar o esgotamento dos assuntos relacionados com a natureza do corpus selecionado. Isto fica claro se considerarmos a vasta multiplicação das imagens dos jogos especulares. Talvez por isso, seja possível considerar a narrativa de "A quinta história" como parte de um processo de relações especulares infinitas e percursos também infinitos. Admitimos, portanto, que esta pesquisa é somente um destes itinerários. Assim, escritas sob o signo da espiral, as obras que compõem o corpus deste artigo trazem imagens difusas e inesperadas de um jogo de espelhos invertidos. O que resta desse jogo é o próprio sujeito, com seus conflitos diante de si e do mundo. 


\section{Obras citadas}

Alonso, Mariângela. O jogo de espelhos na ficção de Clarice Lispector. Annablume, 2017.

Barbosa, Ruy M. Descobrindo a geometria fractal para a sala de aula. Autêntica, 2002.

Basso, Eliana Fátima Corti. Revista Senhor: moderninade e cultura na imprensa brasileira. Secretaria Especial de Comunicação Social, 2005.

Compagnon, Antoine. O demônio da teoria: literatura e senso comum. Traduzido por Cleonice Paes Barreto Mourão, U Federal de Minas Gerais, 1999.

Dällenbach, Lucien. Le livre et ses miroirs dans l'oeuvre romanesque de Michel Butor. Archives des Lettres Modernes, 1972.

—. Le recit spéculaire: Essai sur la mise-en-abyme. Seuil, 1977.

-. "Intertexto e autotexto." Traduzido por Clara Crabbé Rocha. Intertextualidades, no. 27, 1979, pp. 51-76.

Eco, Umberto. "Sobre os espelhos." Traduzido por Beatriz Borges. Sobre os espelhos e outros ensaios. Nova Fronteira, 1989, pp. 11-37.

"Entrevista completa com Clarice Lispector (1977)." YouTube, Entrevistador Júlio Lerner, 16 jul. 2015, youtube.com/watch? $v=n h n h t h P m L 7 s$.

Escobar, Matthew. "L'abyme différencié: vers une nouvelle approche de la miseen-abyme gidienne." André Gide et la tentation de la modernité, editado por Robert Kopp and Peter Schynder, Gallimard, 2002, pp. 383-95.

Genette, Gérard. Palimpsestes: la littérature au second degré. Seuil, 1982.

Jenny, Laurent. "A estratégia da forma." Traduzido por Clara Crabbé Rocha, Intertextualidades, no. 27, 1979, pp. 5-49.

Gide, André. Les-faux monnayeurs: roman, récits et soties, oeuvres lyriques. Gallimard, 1958.

Kahn, Daniela M. "Possibilidades e limitações da narrativa em A quinta história, de Clarice Lispector." Magma, no. 8, 2003, pp. 111-19.

Kristeva, Julia. Introdução à semanálise. Perspectiva, 1974.

Labeille, Véronique. "Manipulation de figure: le miroir de la mise-en-abyme." Figura, no. 27, 2011, pp. 89-104.

Lispector, Clarice. "A explicação que não explica." A descoberta do mundo. Rocco, 1999, pp. 238-40. 
—. "A quinta história.” A legião estrangeira. Rocco, 1999, pp. 74-76.

—. "A quinta história." Casa e Jardim, no. 69, outubro 1960, p. 6.

-. "A quinta história." Senhor, no. 4, abril 1962, p. 3.

—. Laços de família. 11th ed. José Olympio, 1979.

Nunes, Aparecida M. Clarice Lispector jornalista: páginas femininas e outras páginas. Senac, 2006.

Ribeiro, Amanda Gonçalves. "Homotetia." Brasil Escola, brasilescola.uol. com.br/matematica/homotetia.htm.

Ricardou, Jean. Pour une théorie du nouveau roman. Seuil, 1971.

Rimbaud, Arthur. "Carta a Georges Izambard (13 de maio de 1871)." Traduzido por Marcelo Jacques de Moraes, Alea, vol. 8, no.1, 2006, dx.doi.org/10.1590/S1517-106X200600010001.

Rosenbaum, Yudith. "As metamorfoses do mal em Clarice Lispector." Revista USP, no. 41, 1999, pp. 198-206.

Santos, Marinês R., e Joana Maria Pedro. "Domesticidade moderna e relações de gênero: o discurso funcionalista na revista Casa \& Jardim durante as décadas de 1950 e 1960." Anais do VIII Congresso Iberoamericano de Ciência, Tecnologia e Gênero, UTFPR, 2010, pp. 1-17.

Souza, Neusa Santos. "O estrangeiro: nossa condição." O estrangeiro, editado por Catarina Koltai, Escuta, 1998, pp. 155-63.

Zuquete, Afonso Eduardo Martins. Armorial lusitano: genealogia e heráldica. Enciclopédia, 1961. 